\title{
Research on Non Statutory Welfare Monetization of Family Business
}

\author{
Jianwu Zhou ${ }^{1, \mathrm{a}}$ and Kaiyuan Kuang ${ }^{2, \mathrm{~b}^{*}}$ \\ ${ }^{1}$ School of Business Administration, Zhejiang University of Finance and Economics, Hangzhou, \\ China, including country \\ ${ }^{2}$ School of Business Administration, Zhejiang University of Finance and Economics, Hangzhou, \\ China, including country \\ a675038348@qq.com, b675038348@qq.coml
}

Keywords: Family business; Non statutory welfare; Monetizationt

\begin{abstract}
During the practice of welfare management of family business, the monetization trend has become an important issue that must be addressed in the human resource management. Based on actual investigation, this paper analyzes the basic status quo of non statutory welfare for employees in family business, and makes initial exploration of the main causes of the status quo of non statutory welfare.Finally, corresponding countermeasures to improve the non statutory welfare monetization for employees in family business are proposed on the three aspects of recovering the original functions of welfare, the dynamic management of point based system and improving the employee satisfaction.
\end{abstract}

\section{Introduction}

In the welfare management practice, the monetization tendency of Chinese enterprises' welfare can be traced back to the reform and restructuring of state-owned enterprises after the mid-1990s. Reform and development of practice has forced the related theoretical research. Jia Guangbao et.al (1998) [1]studied the issues with regard to the distribution monetization of enterprises' welfare houses, they analyzed the disadvantages of welfare distribution under the planned economic system and the advantages and disadvantages of implementing housing physical welfare monetization, and put forward the concrete suggestions to realize welfare monetization. The two scholars Hao Wanlu, Zhao Jinlu (1999) [2]suggested that welfare monetization is the inevitable trend of social economic monetization, the mechanic selection of efficiently allocating consumption resources as well as the inevitable choice to improve the welfare utility. Cao Hon- gren (1999) [3] pointed out that the welfare monetization is the necessity of welfare reform. The study of Guan Shilian (2000) [4] is that, under the planned economic system, the physical distribution method of welfare system has caused a great waste of welfare resources; therefore, under the condition of market economy, welfare rationing monetization will improve the fairness, rationality and effectiveness of welfare resource allocation. Cao Mulan (2002) [5] listed the defects of issuing physical benefits, proposed to issue policies to prohibit physical distribution, and advocated monetization distribution. Liu Xin (2001) [6]argued that under the condition of market economy, corporate welfare need to be monetized, but should not be monetized completely. In his view, the "low wages, high welfare" of Chinese enterprises is actually to design enterprise welfare in the thinking way of planned economy, it makes the functions of enterprise welfare unable to play its due effect under the condition of market economy, therefore, the practice that enterprises introduce "welfare salary monetization" obviously oversimplifies the design of enterprise welfare system. Xu Dawei (2013) [7] also thinks implementing employee welfare monetization possesses the advantages of meeting the multifaceted, personalized needs of all staff, stabilizing teams, building a harmonious society, enhancing the accuracy of the financial accounting, etc. Shang Jiachen (2014) [8] argues that carrying out the monetization reform of welfare system and gradually canceling physical welfare is an irresistable trend of the reform of modern national compensation system, and also helps to establish a more mature welfare culture and a more formal 
welfare system. Improving the transparency of labor remuneration with welfare monetization is the fundamental solution of preventing "welfare corruption".

In conclusion, it can be found through the document research that the research with regard to the welfare management of China's family business especially the non statutory welfare monetization, etc., seems to be not enough, but in the practice of welfare management of family business, the related problems have become important topics their human resource management must face, under the social background that employee welfare accounts for the rising proportion of staff salary, employee welfare is also the fundamental measure for family business to attract, retain and motivate talents, therefore, paying attention to the research concerning the welfare management of family business especially the non statutory welfare monetization has important theoretical significance and practical significance.

\section{The Basic Status Quo of Welfare Monetization for Employees in Family Business}

In order to analyze the basic status quo of welfare monetization for employees in family business, we chose regions like Zhejiang and Guangdong with rapid development of family business to conduct field investigation. 500 questionnaires were issued during the investigation, while 397 effective questionnaires were recovered, accounting for $79.4 \%$ of total number. Among the respondents, $41.3 \%$ were frontline employees, $32.5 \%$ were basic management, and $26.2 \%$ were senior management. For the convenience of research, we mainly investigate related amount of welfare items (mainly including the housing welfare, transportation welfare, communication welfare, off-job training welfare and commercial compensatory endowment insurance welfare) in family business and total welfare, but it does not involve the welfare that cannot be converted into money, such as vacation, and based on that, we can calculate the proportion of welfare monetization for employees in family business. Here, the proportion of welfare monetization refers to the proportion of welfare enjoyed by the employees which has already been converted into money in the total amount of various welfares. Therefore, in the family business, in the family business, the proportion of welfare monetization for employees at different levels refers to the proportion of welfare enjoyed by employees at different levels which has been converted into money in the total amount of various welfares provided by the family business to these employees. The proportion of welfare monetization items for employees at different levels in the family business can be derived in the same manner. See Tables 1 and 2 for related investigation data. Therefore, we can determine the basic situation of welfare monetization proportion for employees in the family business.

Table 1 The investigated sample of family businesses

\begin{tabular}{|c|c|c|c|}
\hline Management layer & Line staff & Executive & Senior executive \\
\hline $\begin{array}{c}\text { The monetization proportion of } \\
\text { welfare }(\%)\end{array}$ & $91.13 \%$ & $68.62 \%$ & $64.36 \%$ \\
\hline
\end{tabular}

Table 1 shows that among the investigated sample family businesses, the monetized welfare enjoyed by employees at different levels accounts for more than half of the total amount of various welfares, which is higher than $60 \%$, and the average proportion is around $74.7 \%$. This also indicates that among the welfares enjoyed by the family business employees, less than $30 \%$ are indirect objects and services provided by the company, while most welfares are monetized. The above statistics data also reflect another issue: the welfare monetization phenomenon for the basic frontline employees is more prominent, while the monetization trend is not that obvious for the middle and senior management. 
Table 2 The monetization proportion of welfare

\begin{tabular}{|c|c|c|c|}
\hline Management layer & The monetization proportion of & The monetization proportion of & The monetization proportion of \\
welfare of the Line staff $\%)$ & welfare of the Executive $(\%)$ & of the Senior executive \\
$(\%)$
\end{tabular}

In accordance with Table 2, we can also see that for the frontline employees, the monetization proportion of housing welfare is as high as $92.72 \%$, the monetization proportions of transportation welfare and communication welfare are $90.61 \%$ and $90.63 \%$ respectively, the monetization proportions of off-job training and commercial compensatory insurance are, and the monetization proportion of other welfare items is $70.05 \%$; for the basic management, the monetization proportion of housing welfare is $76.53 \%$, the monetization proportions of transportation welfare and communication welfare are $80.26 \%$ and $85.75 \%$ respectively, the monetization proportions of off-job training and commercial compensatory insurance are $40.07 \%$ and $100 \%$ respectively, and the monetization proportion of other welfare items is $27.62 \%$; for the senior management, the monetization proportion of housing welfare is $72.58 \%$, the monetization proportions of transportation welfare and communication welfare are $83.65 \%$ and $56.73 \%$ respectively, the monetization proportions of off-job training and commercial compensatory insurance are $39.67 \%$ and $100 \%$ respectively, and the monetization proportion of other welfare items is $21.33 \%$. The above statistics show that in family business, the employee welfare presents dual differentiation based on the position, and the welfare monetization also presents dual differentiation accordingly. The company does not provide off-job training and commercial compensatory insurance to the frontline employees, which shows that family business only provides the basic welfare system to the frontline employees in accordance with the national law, which does not involve the promoting welfare system.

\section{Conclusion}

The above result shows that restricted by the company's own economic strength, the family business, especially small family business, tends to provide non-statutory welfare to the employees through welfare monetization, while welfare monetization distribution standard is based on the title and position. This kind of welfare system design has its rational property, but also has its defects, which are mainly presented as: first of all, the monetization level for non-statutory welfare is high, on the one hand, it blurs the boundary between direct and indirect compensations for employees in family business, and on the other hand, the distribution of monetization welfare based on title and position will also further increase the income gap between employees at different levels, weaken the original function of welfare and reduce the employees' sense of belonging. Secondly, in family business, the monetization of non-statutory welfare has ignored the individual difference of employees, and significantly reduced the motivational effects of non-statutory welfare. Thirdly, in family business, the design of non-statutory welfare has ambiguous standard, and most non-statutory welfares are designed by the company with low participation from the employees. Therefore, it is necessary to strengthen the management of monetization of non-statutory welfare for employees in family business. 
Recover the Original Functions of Welfare, Reestablish the Boundary between Direct and Indirect Compensations, and Improve the Employees' Sense of Belonging. During construction of non-statutory welfare system, the family business should adequately consider the working enthusiasm of many frontline employees, and avoid further expand the income gap caused by welfare monetization. Part of welfare can be distributed based on title and position, but the original company object welfare should be equally distributed to the employees to reduce the compensation gap between employees and improve their sense of belonging. In addition, efforts should also be made to improve the regular management of non-statutory welfare, and various measures should be used to provide adequate object benefits with actual value to the employees(BAI(2010)[9]), such as scale effect, national taxation reducing policy and collective purchase. In addition, the family business should also keep some cultural and entertainment activities with their own characteristics, which can not only highlight the festive atmosphere in traditional holidays, but also transfer the corporate culture and increase cohesion in the manner of entertainment.

In Accordance with the Individual Difference between Employees, A Dynamic Point-Based Welfare Management System should be Built to Carry out the Continuous Motivational Effects of Non-Statutory Welfare. Because the monetization status quo of non-statutory welfare in family business has ignored the individual difference between employees and significantly reduced the motivational effects of non-statutory welfare, therefore, the management approach of dynamic point-based system can be adopted to continuously motivate the employees. In this system, the employee can obtain personal points through performance, while the company will distribute the welfare based on the employees' points. Every year, the employees can obtain various welfares from the company with their points. Therefore, during the process to obtain the welfare points, the employees will make continuous efforts to improve their work performance, which will make the point-based welfare management a beneficial supplementation to the employee performance management in family business, and it can carry out the continuous motivational effects of welfare.

Design Non-Statutory Welfare for Employees in Family Business with the Objective to Improve the Employee Satisfaction. At present, the establishment standard for non-statutory welfare in family business is very ambiguous. With the objective to improve the employee satisfaction, the design of non-statutory welfare in family business should gradually improve the method and procedure of non-statutory welfare design. There is no doubt that is the design of corporate non-statutory welfare does not consider whether the employees are satisfied or their actual attitude, it will be very difficult to realize the goal of welfare design to motivate the employees(CHEN and TIAN(2015)[10]). Therefore, during the design of non-statutory welfare, the decision of whether simply increasing the monetization proportion or increasing the items of non-statutory welfare service and objects should be based on the basic objective to improve the employee satisfaction, and only in this way can it carry out the role of non-statutory welfare in attracting talents, reducing employee turnover rate and obtain competitiveness of the company.

\section{Acknowledgements}

This paper is sponsored by Zhejiang Provincial Natural Science Foundation (No. LY16G020011).

\section{References}

[1] G.B.JIA, and Z.R. Zheng: Shanghai Real Estate, (1998) No.7, p.22.

[2] W.L.HAO ,and J.L. ZHAO: Economic Management Journal,(1999),No.1,p.53.

[3] H.R.CAO :Journal of Jiangsu Institute of Commerce,(1999), No.3, p.66.

[4] S.L.GUAN: The Journal of Humaniti,(2000), No.6, p.154.

[5] M.L.CAO:Jiang Su Tax,(2002), No.4, p.46.

[6] X.LIU :Human Resources Development of China, (2001), No.1, p.18.

[7] D.W.XU:Journal of Beijing Petroleum Managers Training Institute, No.1, p.26.

[8] J.C.TANG:China Social Security,(2014),No.10,p.59. 
[9] Y.L.BAI:Journal of Labor and social security policy, (2010),No.4,p.35.

[10] Q.P.CHEN:Inquiry into Economic Issues,(2015),No.12,p.51. 
